\title{
Social facilitation of pecking and drinking in "satiated" chickens
}

\author{
D. W. RAJECKI, DAVID A. WILDER, ROBERT F. KIDD, and JAMES JAEGER \\ University of Wisconsin, Madison, Wisconsin 53706
}

\begin{abstract}
Pecking in chickens is a ubiquitous response that does not appear to be exclusively linked to any single motivational state. Because of this, certain earlier findings are ambiguous regarding the extent to which socially mediated pecking in chickens extends to theories of social facilitation effects. In the current research, drinking was identified as a possible alternative response for the study of socially mediated consummatory behavior in chickens. Tests of satiated subjects paired with deprived companions (or tested alone) showed that the pattern and relative amount of the social facilitation of drinking conformed exactly to the pattern for pecking. Therefore, it was concluded that socially enhanced consummatory behavior in the chicken can bear on theories of social facilitation.
\end{abstract}

Chickens peck at the ground when eating, grooming, exploring, aggressing, and courting (Feekes, 1972). Chickens also use pecking to differentiate between companions and strangers as early as the first day after hatching (Zajonc, Wilson, \& Rajecki, 1975). Moreover, overfed chicks will peck in the presence of food (Hogan, 1971). Thus, pecking appears to be a general response that is not exclusively linked to a particular motivational state. Since pecking is such a prevalent behavior in chickens, it is not surprising that research on these animals in the area of social influences on consumption has used the peck as the dependent measure. Studies have consistently shown that socially reared chickens eat more in the company of other chickens than they eat when alone (Tolman, 1968a; Tolman \& Wilson, 1965; Wilson, 1968), even when subjects are fed to satiation before the introduction of hungry companions (Bayer, 1929; Fischel, 1927; Katz \& Revesz, 1909, cited in Tinbergen, 1951; Tolman, 1965).

Attempts to explain the social facilitation of pecking have attributed it to imitation (Tolman, 1968b), increased arousal as a function of companions (Zajonc, 1965), or the disinhibiting effect of familiar companions on fear-inhibited responses (Rajecki, Kidd, Wilder, \& Jaeger, in press; Rajecki, Kidd, \& Ivins, Note 1). But since pecking is such a ubiquitous behavior in chickens, a fourth explanation is possible: Increased pecking may simply be a response to any change in the social environment. Social mediation of pecking, then, may occur regardless of the companion bird's behavior, the subject's arousal, or the subject's level of fear. Therefore, before a decision can be made regarding the strengths of the first three interpretations, it would be desirable to rule out the fourth. That is, if increased pecking in chickens is simply a species-specific response to a change in social environment, then findings from chickens may not bear on theories of social facilitation. In this light, it is necessary to demonstrate that social facilitation in chickens is not restricted to pecking, but also occurs in the case of some specialized response that is not common to many stimuli.

Drinking is one such response. Drinking differs from pecking in its topography and relative frequency. Pecks are rapid, short thrusts of the head and beak. Drinks are relatively unhurried, involve a scooping motion, and usually terminate with the raising of the head to aid swallowing (Hunt \& Smith, 1967; Rheingold \& Hess, 1957). Drinks are rare events when compared to the frequently emitted peck. In a study of the most frequent activities of chicks, the percent time spent at pecking, preening, ground scratching, moving, shrill calling, and sleeping were reported, but drinking, because of its low rate, was not mentioned (Hogan, 1971).

Accordingly, drinking may provide a more compelling test of social facilitation effects in chickens. The current research employed the "satiation" paradigm reported by Bayer (1929), Fischel (1927), Tolman (1965) and others. Simply put, hungry or thirsty animals are allowed to peck or drink in isolation until there is a substantial diminution of the rate of their consummatory responses. Then a hungry or thirsty companion is introduced to the situation, and the rate of consummatory responses by the subject is again recorded. If drinking is facilitated by the activities of a thirsty companion, then social facilitation effects in chickens can be considered of general interest for a theory of social facilitation.

\section{METHOD}

Subjects
Subjects were 16 domestic chickens of the Cornish Cross
variety, 28 days of age at the time of testing. They were
obtained from a commercial source on the day of hatching and
were reared in the laboratory on an ad-lib diet of water and
Purina chick starter (except for experimental deprivation). The
sex of the birds was not determined.
Design
Subjects were deprived and then given an opportunity to feed
in isolation. After a period, the subject continued in isolation, or 


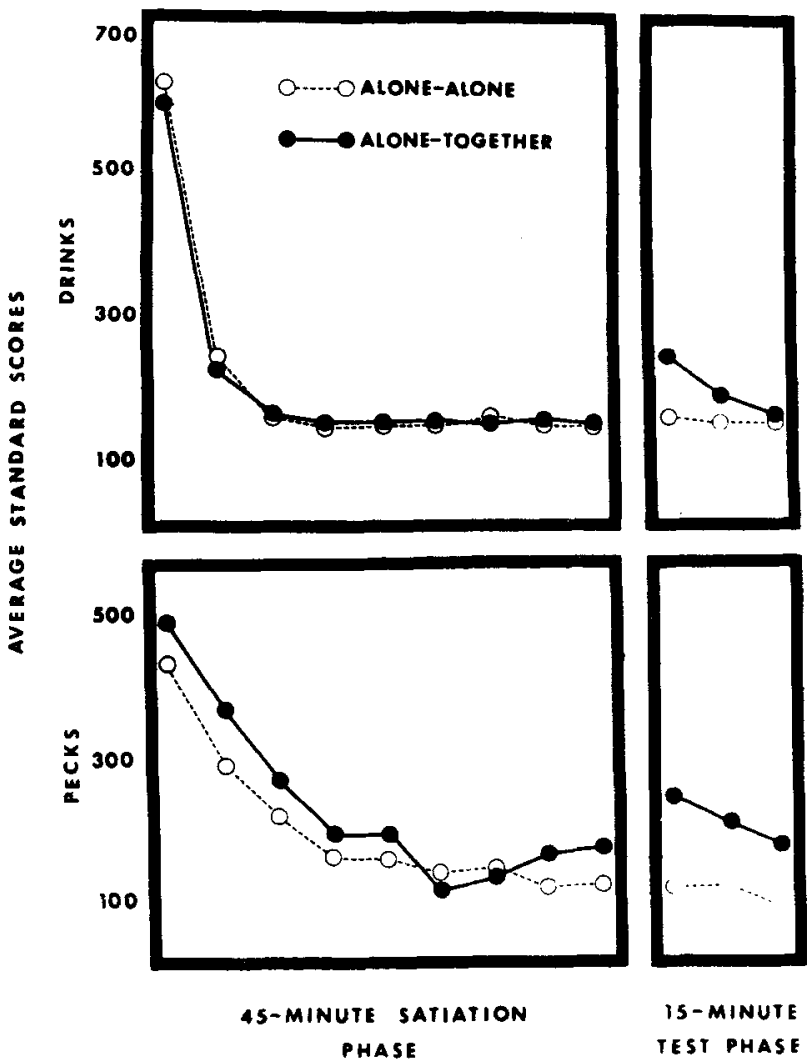

Figure 1. Average standard scores for consummatory responses (pecking and drinking) by birds when alone or with a deprived companion.

was provided with a deprived companion. Of central interest was a comparison of a bird's consummatory behavior when alone or with a deprived companion. A second within-subjects factor examined changes in rate of consumption over time. A final between-subjects factor compared the pattern of pecks to the pattern of drinks (through the standardization of scores) for groups of subjects denied either food or water.

\section{Procedure and Apparatus}

Groups of four animals were housed in four $24 \times 18 \times 18$-in metal cages that were continuously illuminated and heated to $77^{\circ} \mathrm{F}$ by incandescent lamps. Each cage contained removable feeding stations: a 5-in plastic water fount and a 22-in metal food trough. Four continuously illuminated identical cages in a separate room served as test cages.

Testing occurred between 7 and 10 a.m. every other day over a 7-day period. Prior to a test, two of the groups were deprived of food for $16 \mathrm{~h}$, and two of the groups were deprived of water for an equal period. Groups were always denied the same substance over the course of the experiment. At the end of the deprivation period a subject was removed from the home cage and was placed alone in an empty test cage for an adaptation period of $5 \mathrm{~min}$. Then the deprived substance (either a fount of water or a trough of food) was placed in the cage and the number of responses (pecks or drinks) was recorded using hand-held mechanical counters. ${ }^{1}$

Forty-five minutes after the substance was placed in the test cage, the subject was removed briefly and then returned for $15 \mathrm{~min}$ under one of two experimental conditions: either (i) alone, or (ii) together with a companion, a 16-h-and-45-min deprived cagemate. Thus the two test sequences were ALONEALONE (AA) and ALONE-TOGETHER (AT). During the latter $15-\min$ period, the consummatory activity of the subject was also recorded. Each subject was tested in the AA and AT sequences on consecutive test days, with half the subjects in AA first and half in AT first. All subjects also served as the "deprived companion" during the test of some other bird. Thus half the subjects served first in the role of companion, and later in the role of subject. The opposite order (subject-companion) held for the remaining subjects. Two subjects per group of four were tested simultaneously each test day. Since each subject was tested twice, four days of tests were required to complete a group.

In sum, the experiment consisted of mixed factorial design Factors were deprived substance (food or water), social condition (AA or AT), and time (12 5-min blocks). Data from the first $45 \mathrm{~min}$ ( 9 blocks), when the animal was always alone, were analyzed separately from data collected during the remaining $15 \mathrm{~min}$ ( 3 blocks), when the bird was either alone (AA) or with a companion (AT).

\section{RESULTS AND DISCUSSION}

As expected, overall there were more pecks than drinks recorded $(27,984$ vs. 1,235 , respectively). However, since the pattern of responses, rather than the absolute frequency of responses, was of interest, the distribution of pecks and the distribution of drinks were converted to standard scores with means of 200 and standard deviations of 10 . This transformation permitted the direct comparison of social effects on both consummatory activities.

The average number of responses (in standardized form) is shown in Figure 1. Clearly, there was a significant decline in pecking and drinking over the first 45 -min phase of testing $(F=62.22, \mathrm{df}=8 / 112$, $\mathrm{p}<.001)$. Although a satiation criterion was not used to govern experimental events, satiation of a sort was detected. Pecking and drinking ceased for at least $5 \mathrm{~min}$ in 31 of 32 cases (16 subjects tested twice each) during the first phase of testing. Differences were not found during the first $45 \mathrm{~min}$ between the $\mathrm{AA}$ and $\mathrm{AT}$ comparison for number of pecks or drinks, nor for patterns of pecks and drinks.

However, a markedly different pattern of results emerged from an analysis of variance performed on the data from the final 15-min test. As seen in Figure 1, significantly more pecks and drinks were made in the presence of a deprived companion than when subjects were reintroduced to the test cage alone $(F=26.16, \mathrm{df}=$ $1 / 14, p<.001)$. Once again there was no difference in the pattern of the standardized scores for pecking and drinking during this phase of testing. ${ }^{2}$

This experiment employed a paradigm (AA-AT) designed to examine the behavior of satiated birds following the introduction of a deprived conspecific (Bayer, 1929; Fischel, 1927; Katz \& Revesz, 1909; Tolman, 1965). Thus it was necessary to allow the subjects to satiate in isolation before the companion appeared. The results of this procedure provide a clear confirmation of the earlier findings of social facilitation 
in "satiated" chickens. More importantly, they show that social facilitation in chickens is probably a product of a general process not confined to the all-purpose behavior of pecking. However, such data do not provide for a distinction between the three interpretations of social facilitation effects noted earlier (for discussions of the interpretations see Brown \& Kiely, 1974, and Rajecki et al., in press).

Still, seven of the eight subjects in groups deprived of water drank more in the presence of a thirsty companion than when they spent an identical period alone. This finding for drinking is almost identical to the fact that eight of eight subjects in the food-deprived groups ate more in the presence of hungry companions than when alone. Therefore, the results of this study indicate that social facilitation effects in chickens are not restricted to the ambiguous peck response, and that such effects for pecking can bear on theories of social facilitation, whatever their individual merit.

\section{NOTES}

1. Preexperimental checks on interobserver reliability revealed acceptable levels for pecking (.95) and drinking (1.00).

2. There was also a significant interaction between time and social condition (AA vs. AT) in the second phase of testing, but the theoretical import of this finding for the question at hand is not clear.

\section{REFERENCE NOTES}

1. Rajecki, D. W., Kidd, R. F., \& Ivins, B. Strangers and companions: Differential social effects on "behavioral contagion" and "social facilitation" in chickens, under review.

\section{REFERENCES}

Bayer, E. Beitrage zur Sweikomponententheorie des Hungers. Zeitschrift fur Psychologie, 1929, 122, 1-54.

Brown, C. P., \& Kiely, P. C. The role of early experience and emotionality in social facilitation of pecking in chickens. Animal Behaviour, 1974, 22, 100-109.

Feekes, F. "Irrelevant" ground pecking in agonistic situations in Burmese red jungle fowl (Gallus gallus spadiceus). Behaviour, $1972,43,186-326$.

Fischel. W. Beitrage zur Soziologie des Haushuhns. Biologisches Zentralblatt, 1927, 4, 678-696.

Hogan, J. A. The development of a hunger system in young chicks. Behaviour, 1971, 39, 128-201

Hunt, J. L., Jr., \& Smith, W. J. Pecking and initial drinking responses in young domestic fowl. Journal of Comparative and Phy siological Psychology, 1967, 64, 230-236.

Katz, D. \& Revesz, G. Experimentell-psychologische untersuchgenmit huhnevn. Zeitschrift fur Psychologie, 1909, 50. $51-59$.

Rajecki, D. W., Kidd, R. F., Wilder, D. A., \& Jaeger, J. Social facilitation of feeding in chickens: Effects of imitation arousal, or disinhibition? Journal of Personality and Social Psychology, in press.

Rheingold, H. L., \& Hess, E. H. The chick's "preference" for some visual properties of water. Journal of Comparative and Physiological Psychology, 1957, 50, 417-421.

Tinbergen, N. The study of instinct. Oxford: Clarendon Press. 1951.

Tolman, C. W. Social dominance and feeding behavior in domestic cockerels. Psychological Reports, 1965, $17,890$.

Tolman, $C$. W. The varieties of social stimulation in the feeding behaviour of domestic chicks. Behaviour, 1968a, 30, 275-286.

Tolman, $C$. $W$. The role of the companion in social facilitation of animal behavior. In E. C. Simmel, R. A. Hoppe, \& G. A. Milton (Eds.), Social facilitation and imitative behavior. Boston: Allyn \& Bacon, $1968 b$.

Tolman, C, W. \& Wilson, G. F. Social feeding in domestic chickens. Animal Behaviour, 1965, 13, 134-142.

Wilson, G. F. Early experience and facilitation of feeding in domestic chicks. Journal of Comparative and Physiological Psychology, 1968, 66, 800-802.

Zajonc, R. B. Social facilitation. Science, 1965, 149, 269-274.

Zajonc, R. B. Wilson, W. R. \& Rajecki, D. W. Affiliation and social discrimination produced by brief exposure in day-old domestic chicks. Animal Behaviour, 1975, 23, 131-138.

(Received for publication February 17, 1975 . Revision aceepted June 3, 1975 . 